\title{
中和滴定法による $\mathrm{L}-$ リシン塩酸塩の純度測定の高精度化と不確かさの評価
}

\author{
山㠃 太一 ${ }^{\circledR 1}$, 恵 山 栄 $^{1}$, 高津 章子 ${ }^{1}$
}

\section{1 緒言}

アミノ酸はタンパク質の構成成分であり，アミノ酸の定 量分析は栄養学, 生化学, 臨床検查等で広く行われてきて いる. アミノ酸分析に打ける信頼性確保にはその標準液が 必要であり，精確な標準液を調製するためには，使用する 純物質アミノ酸の評価が不可欠である.

アミノ酸の純度評価法については日本薬局方 ${ }^{11}$ や日本工 業規格 $(\mathrm{JIS})^{2)}$ に非水滴定を用いた測定法が記載されてい るが精密な定量分析を目的としていないため, 厳密な評価 が必要な標準物質開発では, 高精度化が求められる.

本研究では $\mathrm{L}$-リシン塩酸塩の純度測定を日本薬局方の L-リシン塩酸塩の定量法 ${ }^{1}$ を元に検討し, 高精度に純度測 定するための分析法の開発を行った．本測定では高精度に 測定するだけではなく，一次標準測定法3) とされている滴 定法を用い, 滴定溶液にはフタル酸水素カリウム (PHP) （NMIJ CRM 3001-a）を用いることで, 滴定溶液を測定する ことなく, 調製值を用いて測定結果のSIトレーサビリティ を確保した。

$$
2 \text { 実験 }
$$

\section{$2 \cdot 1$ 装置 $\cdot$ 試薬}

滴定装置は京都電子製電位差自動滴定装置 AT-510 を用 い, 電極には複合ダブルジャンクション電極を, 内部液と して $1 \mathrm{~mol} \mathrm{~L}^{-1}$ 塩化リチウム/酢酸溶液を用いた。測定試料 には $\mathrm{L}$-リシン塩酸塩（和光純薬工業製）を用いた。試料調 製には $0.1 \mathrm{~mol} \mathrm{~L}^{-1}$ 過塩素酸/酢酸溶液（関東化学製）及び ギ酸（関東化学製）を用いた。滴定溶液はPHP を酢酸に溶 解して調製した.

\section{$2 \cdot 2$ 純度測定法}

あらかじめ濃度既知の $\mathrm{PHP} /$ 酢酸溶液を用いて中和滴定 で過塩素酸/酢酸の濃度 $\left(C_{\mathrm{HClO} 4}\right)$ を決定した. 試料容器に 試料を入れて, 秤量した後に濃度既知の過塩素酸/酢酸を 加えて秤量し, 加熱して, 塩化水素を除去後に PHP/酢酸

\footnotetext{
${ }^{\circledR}$ E-mail : t-yamazaki@aist.go.jp

${ }^{1}$ 独立行政法人産業技術総合研究所計測標準研究部門 : 305-8563 茨城県つくば市梅園 1-1-1 中央第 3
}

溶液を用いた中和滴定で過剩の過塩素酸を滴定することに より， L-リシン濃度 $\left(\mathrm{mol} \mathrm{g}^{-1}\right)$ を決定することができる. L-リシン塩酸塩は塩化水素を完全に除去すると 2 価のアミ ンとなり，式（1）を用いて純度測定することができる．こ こで $C_{\mathrm{HCIO}}$ は式 $(2$ ）のように表すことができ，最終的な 算出式は式 (3) となる.

$$
\begin{aligned}
& P=\left(w_{\mathrm{HClO} 4} \times C_{\mathrm{HClO} 4}-V_{\mathrm{Lys}} \times C_{\mathrm{PHP}}\right) \times \frac{M W_{\mathrm{Lys}}}{2 \times w_{\mathrm{Lys}}} \\
& C_{\mathrm{HClO} 4}=\frac{V_{\mathrm{blank}} \times C_{\mathrm{PHP}}}{w_{\mathrm{HClO} 4}^{\prime}} \\
& P=\left(\frac{w_{\mathrm{HClO} 4} \times V_{\mathrm{blank}}}{w_{\mathrm{HClO} 4}^{\prime}}-V_{\mathrm{Lys}}\right) \times \frac{C_{\mathrm{PHP}} \times M W_{\mathrm{Lys}}}{2 \times w_{\mathrm{Lys}}}
\end{aligned}
$$

ここで $\mathrm{L}$-リシン塩酸塩の純度 $\left(\mathrm{g} \mathrm{g}^{-1}\right)$ を $P$, 試料測定時 の過塩素酸/酢酸の秤量值 $(\mathrm{g})$ を $w_{\mathrm{HCIO} 4}$, ブランク測定の 過塩素酸/酢酸の秤量値 $(\mathrm{g})$ を $w_{\mathrm{HClO}}^{\prime}$, 試料の秤量值 $(\mathrm{g})$ を $w_{\mathrm{Ly},}$, 過塩素酸/酢酸の濃度 $\left(\mathrm{mol} \mathrm{g}^{-1}\right)$ を $C_{\mathrm{HClO}}, \mathrm{PHP} /$ 酢酸溶液の濃度 $\left(\mathrm{mol} \mathrm{L}^{-1}\right)$ を $C_{\mathrm{PHP}}$, 試料滴定時の滴定量 (L) を $V_{\mathrm{Lyy}}$, ブランク滴定時の滴定量（L)を $V_{\text {blank }}, \mathrm{L}-$ リ シン塩酸塩の分子量を $M W_{\mathrm{Lys}}$ とした。

\section{$2 \cdot 3$ 試料調製と測定}

PHP を秤量して $500 \mathrm{~mL}$ 全量フラスコに入れ, 酢酸で溶 解して滴定溶液を調製した。この際に加えた酢酸も秤量 し, 調製した滴定溶液の密度測定も行った。

$\mathrm{L}$-リシン塩酸塩約 $0.1 \mathrm{~g}$ を秤量し, ギ酸 $2 \mathrm{~mL}$ を加えて溶 解, 秤量後, $0.1 \mathrm{~mol} \mathrm{~L}^{-1}$ 過塩素酸/酶酸溶液を $20 \mathrm{~mL}$ 加え て秤量した．調製溶液をホットスターラーで加熱して塩化 水素を除去した. 放冷後, 酢酸を $35 \mathrm{~mL}$ 加えて, 滴定用の 試料とした.

\section{$2 \cdot 4$ 測定条件の検討}

L-リシン塩酸塩の加熱による塩化水素の除去について検 討を行い, 完全に除去可能な条件を決定した，加熱条件と しては, 湯浴中での $65{ }^{\circ} \mathrm{C}, 80^{\circ} \mathrm{C}$ 及び測定試料のバイアル を直接加熱して約 $100{ }^{\circ} \mathrm{C}$ (直接加熱法)の条件について検 討した．さらに，加熱時間も変えて最適化を行った。 


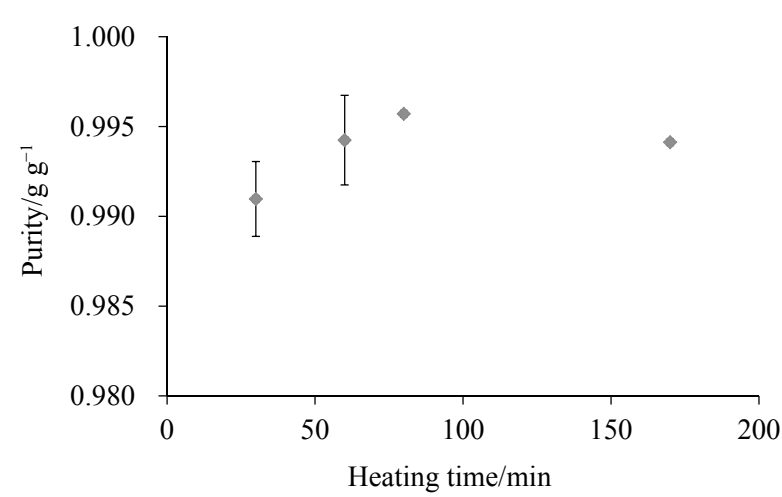

Fig. 1 Effect of the heating time on the obtained purity value

\section{$\mathbf{2} \cdot \mathbf{5}$ 窒素分析法による純度測定}

本測定結果の妥当性確認のためにケルダール法を用いた 窒素分析を行った．窒素分析における分解装置にはゲルハ ルト製 KB8S を用い, 蒸留にはゲルハルト製 Vapodest30を 用いて試料調製した．測定には中和滴定と同様に電位差自 動滴定装置を用いた. 約 $0.05 \mathrm{~g}$ の試料と分解促進剂をケル ダールフラスコに入れ, 硫酸 $10 \mathrm{~mL}$ を加えて加熱分解を 行った. ブランク測定も同様に行った.

分解後, 蒸留して, 発生したアンモニアを $4 \%$ ホウ酸溶 液で捕集した試料を $0.025 \mathrm{~mol} \mathrm{~L}^{-1}$ 硫酸で中和滴定した. 硫酸の評定には炭酸ナトリウムを用いた。

\section{3 結果と考察}

\section{$3 \cdot 1$ 測定方法}

本測定では二つの点に着目して, 信頼性の高い純度測定 法の開発を行った。一つは前処理における脱塩化水素の高 精度化を行うことで, 再現性と信頼性の高い測定結果を目 指した。 二つ目は測定のトレーサビリティを確保すること で測定結果の信頼性の向上を目指した. JIS や日本薬局方 では酢酸ナトリウムを用いているが，本測定では認証標準 物質（CRM）である PHPを用いた。これは酢酸ナトリウ ムを用いる場合は測定の SI トレーサビリティを確保する ために多段階で滴定し, 濃度決定することになるために測 定精度が低下する原因になる可能性がある. そこで調製值 そのものを滴定溶液の濃度とすることで, 測定操作を簡略 化するとともに測定精度の向上を目指した. これらを最適 化することで, より信頼性の高い純度測定を実現した。

\section{$3 \cdot 2$ 試料調製条件の検討}

日本薬局方における L-リシン塩酸塩の定量では短時間で 塩化水素を除去するために除去が不十分な場合に定量值が 低くなることが予想される. そのため, 塩化水素を完全に 除去する必要があり, 試料調製における加熱条件の影響を 検討した. $100{ }^{\circ} \mathrm{C}$ の湯浴中では沸騰による水の混入とバイ
アル自体が安定しないことから直接加熱法で, 加熱還流す る条件で検討を行った。 それぞれの温度で 30 分間加熱し た試料を測定したところ測定結果は $65{ }^{\circ} \mathrm{C}$ では $92.9 \pm 0.5$ $\mathrm{g} \mathrm{g}^{-1}, 80{ }^{\circ} \mathrm{C}$ では $97.1 \pm 0.2 \mathrm{~g} \mathrm{~g}^{-1}$, 直接加熱法の $100{ }^{\circ} \mathrm{C}$ で は99.1 $\pm 0.2 \mathrm{~g} \mathrm{~g}^{-1}$ であった. 高い純度值が得られた条件が 効率良く塩化水素を除去できていると考えられ, 高温で加 熱することで効率良く塩化水素が除去できたと結論付けら れる。

次に最も効率良く塩化水素を除去することができた直接 加熱法における加熱時間が測定純度值に与える影響につい て検討を行った. 加熱時間を 30 分, 60 分, 80 分, 170 分 でそれぞれ実験を行った測定結果を Fig. 1 に示す. 80 分ま では純度值が上昇し, 80 分と 170 分では大きな差が確認さ れなかった．また, 測定ばらつきについても 60 分までは標 準偏差として $0.2 \%$ 以上のばらつきが確認されたが, 80 分 以降では $0.1 \%$ 以下に抑えられていた。 これはほぼすべて の塩化水素が除去され, 平衡化されているためと結論付け ることができる.この結果から直接加熱法で 80 分以上加 熱する条件が最も効率的に塩化水素を除去できたと考えら れる。

一方で, 加熱により過塩素酸/酢酸が純度測定に影響を 与えないことを確認するために加熱時間を 0 分, 45 分, 90 分, 135 分とした時のブランク測定を行った. その結果, 過 塩素酸/酢酸の濃度の測定ばらつきは相対標準偏差として 約 $0.05 \%$ であり, 测定結果に影響を与えない程度であり, 加熱時間に依存しないことが分かる．加熱条件により過塩 素酸/酢酸の濃度に変動はないため, 未加熱の空測定結果 を過塩素酸/酢酸の濃度として純度測定に用いた。

\section{$3 \cdot 3$ 滴定溶液の評価}

滴定溶液の調製は測定結果に直接影響を与えるため, 精 確な滴定溶液を調製するために容量による調製值 $\left(C_{\mathrm{V}}\right)$ と 質量による調製值 $\left(C_{\mathrm{W}}\right)$ の二つの濃度から濃度を決定し た. $C_{\mathrm{V}}$ は式 $(4)$ のように算出し, 測定した $C_{\mathrm{W}}$ では溶液 の密度を用いて式（5）のように算出した.

$$
\begin{aligned}
C_{\mathrm{V}} & =\frac{w_{\mathrm{PHP}}}{M W_{\mathrm{PHP}} \times V} \\
C_{\mathrm{W}} & =\frac{w_{\mathrm{PHP}} \times d}{M W_{\mathrm{PHP}} \times\left(w_{\mathrm{PHP}}+w_{\mathrm{ACOH}}\right) \times 1000}
\end{aligned}
$$

ここで PHP の秤量值 $(\mathrm{g})$ を $w_{\mathrm{PHP}}$, PHP の分子量を $M W_{\mathrm{PHP}}$, 酢酸の容量 $(\mathrm{L})$ を $V$, 密度 $\left(\mathrm{g} \mathrm{L}^{-1}\right)$ を $d$, 酢酸 の秤量值 $(\mathrm{g})$ を $w_{\mathrm{AcOH}}$ とした。算出された滴定溶液濃度は 容量法では $0.070263 \mathrm{~mol} \mathrm{~L}^{-1}$ であり, 質量法では 0.070367 $\mathrm{mol} \mathrm{L}^{-1}$ であった. 二つの調製法間差は $0.2 \%$ 以下であり, 十分な調製精度と考えられる. $C_{\mathrm{V}}$ と $C_{\mathrm{W}}$ の平均值である 
Table 1 Uncertainty table in purity determination by neutralization titration

\begin{tabular}{|c|c|c|c|c|}
\hline Factor & value $x_{i}$ & $\begin{array}{c}\text { Standard } \\
\text { uncertainty } \\
u\left(x_{i}\right)\end{array}$ & Sensitivity coefficient $c_{i}\left(=\partial f / \partial x_{i}\right)$ & $\begin{array}{c}\text { Uncertainty } \\
\text { contribution } \\
u_{i}\left(P_{\text {lys }}\right) \\
=\left|c_{i}\right| u\left(x_{i}\right) / \\
\mathrm{g} \mathrm{g} \mathrm{g}^{-1}\end{array}$ \\
\hline $\begin{array}{l}\text { Mass of } \mathrm{HClO}_{4} / \mathrm{AcOH} \\
\text { solution }\left(w_{\mathrm{HClO} 4}\right)\end{array}$ & $21.115225 \mathrm{~g}$ & $0.000045 \mathrm{~g}$ & $V_{\text {blank }} / w_{\mathrm{HClO} 4}^{\prime} \times C_{\mathrm{PHP}} \times M W_{\mathrm{Lys}} / 2 / w_{\mathrm{Lys}}$ & 0.00000 \\
\hline $\begin{array}{c}\text { Mass of } \mathrm{HClO}_{4} / \mathrm{AcOH} \\
\text { solution }\left(w_{\mathrm{HClO} 4}^{\prime}\right)\end{array}$ & $10.61922 \mathrm{~g}$ & $0.000045 \mathrm{~g}$ & $-w_{\mathrm{HClO} 4} \times V_{\mathrm{blank}} / w_{\mathrm{HClO} 4}^{\prime} \times C_{\mathrm{PHP}} \times M W_{\mathrm{Lys}} / 2 / w_{\mathrm{Lys}}$ & 0.00008 \\
\hline Mass of sample ( $\left.w_{\text {Lys }}\right)$ & $0.10053 \mathrm{~g}$ & $0.0000056 \mathrm{~g}$ & $-P_{\mathrm{Lys}} / w_{\mathrm{Lys}}$ & 0.00006 \\
\hline $\begin{array}{l}\text { Titer in sample } \\
\text { measurement }\left(V_{\mathrm{Lys}}\right)\end{array}$ & $0.0131779 \mathrm{~L}$ & $0.0000050 \mathrm{~L}$ & $-C_{\mathrm{PHP}} \times M W_{\mathrm{Lys}} / 2 / w_{\mathrm{Lys}}$ & 0.00032 \\
\hline $\begin{array}{l}\text { Titer in blank } \\
\text { measurement }\left(V_{\text {blank }}\right)\end{array}$ & $0.0144964 \mathrm{~L}$ & $0.0000050 \mathrm{~L}$ & $w_{\mathrm{HClO} 4} / w_{\mathrm{HClO} 4}^{\prime} \times C_{\mathrm{PHP}} \times M W_{\mathrm{Lys}} / 2 / w_{\mathrm{Lys}}$ & 0.00063 \\
\hline $\begin{array}{l}\text { Concentration of PHP } \\
\text { solution }\left(C_{\mathrm{PHP}}\right)\end{array}$ & $0.070315 \mathrm{~mol} \mathrm{~L}^{-1}$ & $0.00005 \mathrm{~mol} \mathrm{~L}^{-1}$ & $P_{\mathrm{Lys}} / C_{\mathrm{PHP}}$ & 0.00071 \\
\hline $\begin{array}{l}\text { Concentration by } \\
\text { volumetric method }\left(C_{\mathrm{V}}\right)\end{array}$ & $0.070263 \mathrm{~mol} \mathrm{~L}^{-1}$ & $0.00002 \mathrm{~mol} \mathrm{~L}^{-1}$ & & \\
\hline $\begin{array}{l}\text { Concentration by } \\
\text { gravimetric method }\left(C_{\mathrm{W}}\right)\end{array}$ & $0.070367 \mathrm{~mol} \mathrm{~L}^{-1}$ & $0.00001 \mathrm{~mol} \mathrm{~L}^{-1}$ & & \\
\hline $\begin{array}{l}\text { Difference between the } \\
\text { preparation methods }\left(C_{\mathrm{b}}\right)\end{array}$ & $0.070315 \mathrm{~mol} \mathrm{~L}^{-1}$ & $0.00005 \mathrm{~mol} \mathrm{~L}^{-1}$ & & \\
\hline $\begin{array}{l}\text { Molecular weight of Lys } \\
\qquad\left(M W_{\text {Lys }}\right)\end{array}$ & 182.4686 & 0.0017 & $P_{\mathrm{Lys}} / M W_{\mathrm{Lys}}$ & 0.00001 \\
\hline Effect of temperature ( $\left.V_{\text {temp }}\right)$ & $100 \%$ & $0.01 \%$ & 1 & 0.00014 \\
\hline
\end{tabular}

$0.070315 \mathrm{~mol} \mathrm{~L}^{-1}$ を滴定溶液の濃度として用いた。酢酸の 密度は温度による影響を非常に大きく受けるため ${ }^{4)}$, 調製 及び測定環境における温度を可能な限り一定に実験を行っ た.

\section{$3 \cdot 4$ 不確かさの評価}

本測定における不確かさを一般的な評価方法に基づき, 算出し, 結果に影響を与える要因について評価した $。$ 。測 定におけるバジェット表を Table 1 に示した. 標準不確か さは純度算出に必要な項をすべて含む式 $(3)$ を元に算出 した. 過塩素酸/酢酸溶液 $\left(w_{\mathrm{HClO} 4}, w_{\mathrm{HClO} 4}^{\prime}\right)$ 及び試料の科 量 $\left(w_{\text {Lys }}\right)$ の不確かさはJCSS 校正 ${ }^{6}$ による天秤の秤量值の 不確かさを用いた. 秤量の不確かさは非常に小さく, 測定 に対して十分な精度で秤量したことが分かる. 試料測定 $\left(V_{\mathrm{Lys}}\right)$ 及びブランク測定 $\left(V_{\text {blank }}\right)$ の不確かさは各測定にお ける繰り返し測定の標準偏差を標準不確かさとした。これ ら測定が合成標準不確かさに与える影響は $0.03 〜 0.07 \%$ であり，測定によるばらつきが合成標準不確かさに大きく 影響しているが, $0.1 \%$ 以下で高い再現性で測定できた. 滴定溶液調製 $\left(C_{\mathrm{PHP}}\right)$ の不確かさは容量法 $\left(C_{\mathrm{V}}\right)$ と質量法 $\left(C_{\mathrm{W}}\right)$ の調製不確かさに加えて, 二つの調製法間差 $\left(C_{\mathrm{b}}\right)$ も 考慮して, 不確かさを算出した。容量法による標準液調製
では試料量, 分子量 ${ }^{6)}$, 標準物質の純度, 溶媒量の不確か さを考慮した，質量による標準液調製では容量調製におけ る不確かさ項目に加えて密度の不確かさを考慮した．調製 方法間差は二つの調製值の差の半分の值を不確かさとして 見積もった．滴定溶液調製の不確かさは約 $0.07 \%$ 合成標 準不確かさに影響し, 最も大きな不確かさ要因となってい る. 試料の分子量 $\left(M W_{\mathrm{Lys}}\right)$ の不確かさは IUPAC $(2010)^{7)}$ で示されている不確かさを用いた。調製溶媒である酢酸の 密度は温度の影響を受けやすいために実験中の温度範囲を モニターし, 温度変化による滴定溶液の体積変化における 不確かさ $\left(V_{\text {temp }}\right)$ も考慮した．本測定における体積変化の 不確かさは非常に小さいがこれは測定環境を恒温にして測 定したために不確かさを小さく抑えることができた．酢酸 の密度は温度により大きく影響を受けることが知られてい $ろ^{4)}$. そのため, 本測定の際には測定時における温度を恒 温に保つことで, 高精度に測定可能と考えられる.

これらのすべての不確かさを合成すると純度值に対する 合成標準不確かさは約 $0.10 \%$ であり, 純度值を $0.9985 \pm$ $0.0010 \mathrm{~g} \mathrm{~g}^{-1}$ と算出でき, すべての不確かさ要因を加味し た場合でも良好な測定結果が得られた。 また，各要因の標 準不確かさは相対值として 5 桁以上で評価でき, 十分精度 であることが分かる。 
Table 2 Measurement results in each method

\begin{tabular}{ccc}
\hline Analytical method & Purity/g g & $\begin{array}{c}\text { Standard uncertainty/ } \\
\mathrm{g} \mathrm{g}^{-1}\end{array}$ \\
\hline $\begin{array}{c}\text { Neutralization } \\
\text { titration method }\end{array}$ & 0.9985 & 0.0010 \\
Kjeldahl method & 0.9982 & 0.0011 \\
\hline
\end{tabular}

\section{$3 \cdot 5$ 測定結果と窒素分析法による測定結果との比較}

ケルダール法では得られる窒素量から窒素含有化合物の 純度值を求めることができる ${ }^{8)}$ 。そこで, 得られた純度值 とケルダール法を用いた窒素分析法から求めた純度值を比 較し, 測定結果の妥当性確認を行った. 各測定法の結果を Table 2 に示した. 各測定法における測定結果はばらつき の範囲内で一致し, 本研究で確立した条件で純度測定した 結果が十分信頼性の高い值であると考えられる.

\section{4 結 言}

本研究では L-リシン塩酸塩について滴定法を用いて純度 評価した. その結果, 測定試料調製における塩化水素の除 去率が純度に与える影響が非常に大きいことを明らかに し, 十分に塩化水素を除去できる条件を確立することで, 高精度な純度評価法を開発した。 また, PHP（NMIJ CRM 3001-a）を用いることで測定の SI トレーサビリティも確保 して測定した.

さらに， L-リシン塩酸塩について本測定法と窒素分析の 結果と比較したところ, 測定ばらつきの範囲内で一致する ことを確認し, 測定法の妥当性を確認することができた. この結果から, 同様の手法で他のアミノ酸塩酸塩について も高精度に純度測定できると考えられる。

\section{文献}

1) 第十六改正日本薬局方, L-リシン塩酸塩, p. 1388 (2011).

2) JIS K 9050, L-ヒスチジン塩酸塩一水和物 (試薬), (1993).

3) T. J. Quinn : Metrologia, 34, 61 (1997).

4) D. R. Lide : "CRC Handbook of Chemistry and Physics”, Edited by CRC Press, 89th, p. 15-25 (2008).

5) EURACHEM/CITAC Guide CG4: Quantifying Uncertainty in Analytical Measurement, 3rd Edition (2012).

6) JCSS (Japan calibration service system), available from <http://www.iajapan.nite.go.jp/jcss/outline/ index.html $>$.

7) M. E. Wieser, T. B. Coplen : Pure Appl. Chem., 83, 359 (2011).

8) A. Takatsu, E. Sakae, S. Mika : Accred. Qual. Assur., 13, 409 (2008).

\title{
Accurate Purity Analysis of L-Lysine Hydrochloride by Using Neutralization Titration and Uncertainty Evaluation
}

\author{
Taichi YAMAZAKI $^{1}$, Sakae EyAMA ${ }^{1}$ and Akiko TAKATSU ${ }^{1}$
}

${ }^{\circledR}$ E-mail : t-yamazaki@aist.go.jp

\begin{abstract}
${ }^{1}$ National Metrology Institute of Japan (NMIJ), National Institute of Advanced Industrial Science and Technology (AIST), 1-1-1, Umezono, Tsukuba-shi, Ibaraki 305-8563
\end{abstract}

(Received June 11, 2012; Accepted July 25, 2012)

The quantitative analysis of amino acid is widely used in many analysis fields. Purity evaluations of amino acids are essential to prepare accurate calibration solutions for amino acid analysis. In this paper, the purity determination of L-lysine hydrochloride with using neutralization titration is discussed. Removing hydrogen chloride from a sample solution of L-lysine hydrochloride is important to determine the purity by neutralization titration. For an accurate purity determination of L-lysine hydrochloride, the condition in sample preparation was optimized. Under the optimized conditions, the purity of L-lysine hydrochloride could be determined with $0.03 \%$ to $0.07 \%$ of repeatability. The uncertainty of the measurement could be estimated at about $0.1 \%$. Moreover, the determined purity value was in good agreement with the purity value from nitrogen analysis. The optimized condition is valid for the purity analysis of lysine hydrochloride.

Keywords: titration; L-lysine hydrochloride; purity analysis; amino acid; primary method. 